\title{
Chinese Acupuncture in Treatment of Bell's Palsy Clinical Study
}

\author{
Hadi Mohammed Mujlli' ${ }^{1}$, Abdulraman Sallam Alkubaty ${ }^{2}$ \\ ${ }^{1}$ Thamar Medical College, Thamar University, Dhamar, Yemen \\ ${ }^{2}$ Sana'a Medical College, Sana'a University, Sana'a, Yemen \\ Email: Dr.hadimujlli@gmail.com, Neuroepileptic.center@gmail.com
}

How to cite this paper: Mujlli, H.M. and Alkubaty, A.S. (2017) Chinese Acupuncture in Treatment of Bell's Palsy Clinical Study. Open Access Library Journal, 4: e3714. https://doi.org/10.4236/oalib.1103714

Received: June 6, 2017

Accepted: June 26, 2017

Published: June 30, 2017

Copyright (C) 2017 by authors and Open Access Library Inc.

This work is licensed under the Creative Commons Attribution International License (CC BY 4.0).

http://creativecommons.org/licenses/by/4.0/

\begin{abstract}
Objective: To observe the therapeutic effects of acupuncture for treatment of different stages of Acute Bell's palsy, and its relationship to age and sex. Patients and Methods: 152 patients of Bell's palsy, were acute cases in different grade of paralysis. Following up with combined drugs and acupuncture therapy for one month, which were diagnosed clinically and proved by electromyography EMG, these cases of acute Bell's palsy were collected from Apr. 2016 to Feb. 2017 in Thamar governorate $100 \mathrm{~km}$ south to Sana'a capital city of Yemen. These cases were divided in to three groups, according to HousBrackmann grading system, HBGS: 1-marked improvement (very good) when patients improved completely within two weeks; 2-mild improvement (good) when patients improved within one months; 3-resistant in which there is no improvement within one months. EMG was used in diagnosis various stages of peripheral facial paralysis, evaluation of prognosis and guidance in clinical treatment with combined drugs and Chinese acupuncture for one month of clinical follow up. Statistical significance was assessed by P-values for Chi square test analysis by Epi info statistical analysis of single and stratified tables. Results: During the study period 152 patients were diagnosed as acute Bell's palsy. Of these 81 (53\%) cases were females and 71 (47\%) were males. The improvement of acute facial paralysis was related to patients' ages which were divided as three groups: $1-29$ y, $30-59$ y, more than 60 years old. The results shows that the younger age group have a better chance to improve; $1^{\text {st }}$ group $61(40.5 \%), 2^{\text {nd }}$ group $48(31.5 \%)$ and $3^{\text {rd }}$ group $43(28 \%)$. Conclusion: The electro-acupuncture in treatment of acute stage peripheral facial paralysis is effective and the improvement in the young age group shows very good improvement than old age.
\end{abstract}

\section{Subject Areas}

Medical Genetics 


\section{Keywords}

Bell's Palsy, Acupuncture, Age, Sex, Facial Paralyses, Improvement

\section{Introduction}

Acupuncture is a choice for treatment of patients suffering from Bell's palsy; therapeutic effectiveness of the combined method of acupuncture with otopoints is far better than the therapeutic methods used alone [1]. Acupuncture is an ancient healing system developed over thousands of years in china and other eastern countries which is increasingly being recognized as "effective" by western health professionals and patients. Treatment can benefit almost any ill person as long as degeneration process is not too extensive. It's very significant that EMG was used in diagnosis various stages of peripheral facial paralysis, evaluation of prognosis and guidance in clinical treatment [2]. Bell's palsy is the most common disease of the facial nerve; it can strike almost any one at any age; however, it disproportionably attacks pregnant women [3]. In addition to one-sided facial paralysis with possible inability to close eye, symptoms of Bell's palsy may include facial pain [4], tearing, drooling, hypersensitivity to sound in the affected ear and impairment of taste. It's presumably due to an inflammatory reaction in or around the facial nerve near the stylomastoid foramen when the acupuncture initiated within three days' post-onset, $100 \%$ of the patients were cured or there was marked improvement [5]. The demyelination triggered by viral infection may be responsible [6]. Early diagnosis and treatment within three days of the onset of the paralysis are necessary for maximal efficacy of combined acyclovir and prednisolone therapy for Bell's palsy [7]. There is no relationship of Bell's palsy and sex, age, diabetic and hypertension [8]. With removal of pathogenic factors and the recovery of the body resistance, stronger stimulation or electro-acupuncture can be used to accelerate the cure [9].

\section{Patients and Methods}

152 patients of Bell's palsy, were acute cases in different grade of paralysis, all were patients with facial dysfunction from different causes, included the mild dysfunction (Global grade 2) and total paralysis according to Hous-Brackmann grading system (HBGS). Follow up with combined drugs and acupuncture therapy for one month, that diagnosed clinically and proved by EMG, these cases of acute Bells palsy were collcted from Apr 2016 to Feb 2017 in thamar governorate $100 \mathrm{~km}$ south to Sanaa capital city of Yemen. The acupuncture points used in this research were: body acupuncture; Yan bai (GB20), Jia che (ST6), Di cang (ST4), He gu (L14), Tai chong (LR3), Ju lia (ST3), and Cheng jiang (CV24). Modification: for pain behind the ear Ye feng (TE17) is added, for the inability to close the eye Yang bai (GB14), and Cuan zhu (BL2), are added, for flattening of nasolabial fold Shui gou (GV26) is added, for prolong duration of illness, $\mathrm{Zu}$ san li (ST36) is added. For pain, redness of eye with facial palsy, Si bai ST2) is added. 
These cases were divided in to three groups; "according to HBGS" 1-marked improvement (very good) when patients improved completely within two weeks. 2-mild improvement (good) when patients improved within one months. 3 resistant in which there is no improvement within one months. Epi info 7 statistical method was used for analysis of data. Statistical significance assessed by $\mathrm{P}$-values for Chi square test analysis by Epi info statistical analysis of single and stratified tables.

\section{Results}

- Improvement of Bell's palsy after combined treatment of drugs and acupuncture therapy in a period of one month follow up related to sex as shown in Table 1.

- Improvement of acute Bell's palsy treated with acupuncture therapy in a period of one month follow up, related to age as shown in Table 2.

- Improvement of Bell's palsy after combined treatment of drugs and acupuncture therapy in a period of one month follow up as shown in Figure 1.

- Relationship between male and female regarding he differences of improvement of the facial paralysis related to sex as shown in Figure 2.

- Improvement of Bell's palsy related to the age of patients shows more toward the young age group comparing to the middle and old age group as shown in Figure 3.

\section{Discussion}

According to the facial paralysis scale; House - Brackmann Grading System HBGS [10], used to evaluate the improvement of acute Bell's palsy that including in this research, which shows very good improvement post one month of acupuncture therapy, markedly obvious effective in treatment of acute facial parlay-

Table 1. Improvement of acute Bell's palsy related to sex.

\begin{tabular}{ccccc}
\hline \multirow{2}{*}{ Sex } & \multicolumn{3}{c}{ Improvement } & \multirow{2}{*}{ Total } \\
\cline { 2 - 4 } & Very good & Good & Non-improv & \\
\hline Female & 42 & 24 & 15 & 81 \\
Male & 34 & 23 & 14 & 71 \\
Total & 76 & 47 & 29 & 152 \\
\hline
\end{tabular}

Table 2. Improvement of acute Bell's palsy related to age.

\begin{tabular}{ccccc}
\hline \multirow{2}{*}{ Age } & \multicolumn{3}{c}{ Improvement } & Total \\
\cline { 2 - 4 } & Very good & Good & Non-improv & 61 \\
$3-29$ & 35 & 12 & 14 & 48 \\
$>60$ & 19 & 18 & 11 & 43 \\
Total & 12 & 15 & 16 & 152 \\
\hline
\end{tabular}



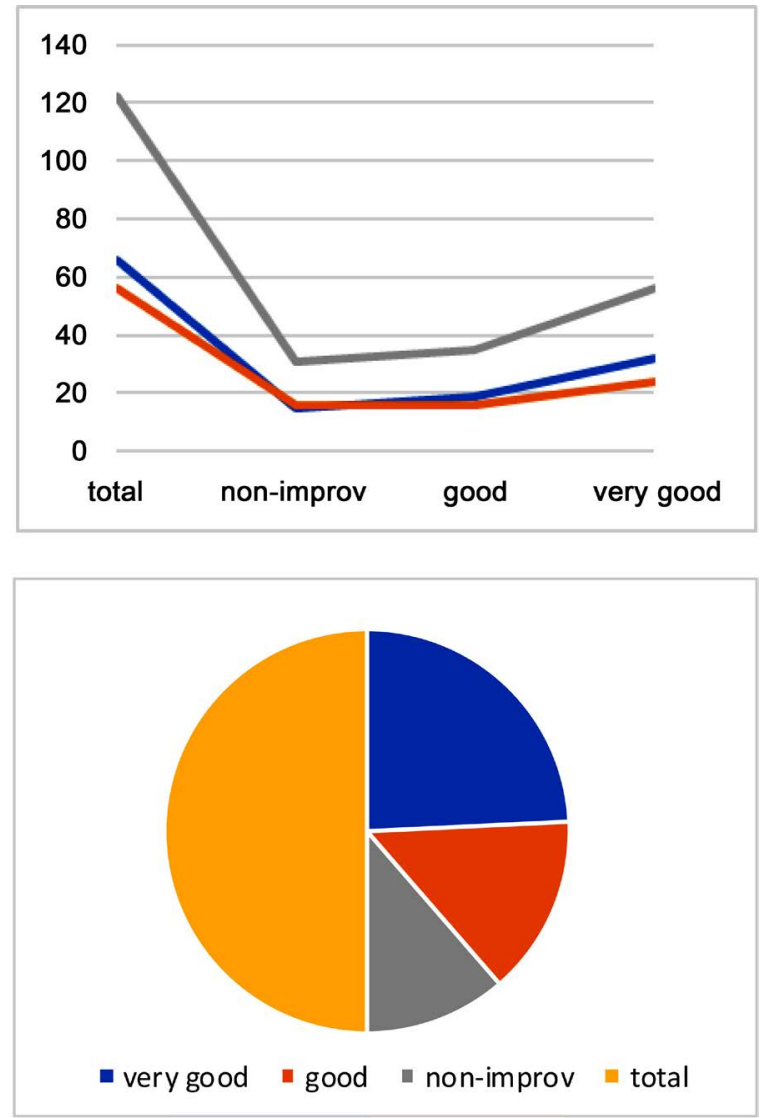

Figure 1. Improvement of acute Bell's palsy after acupuncture therapy of one month period follow up.

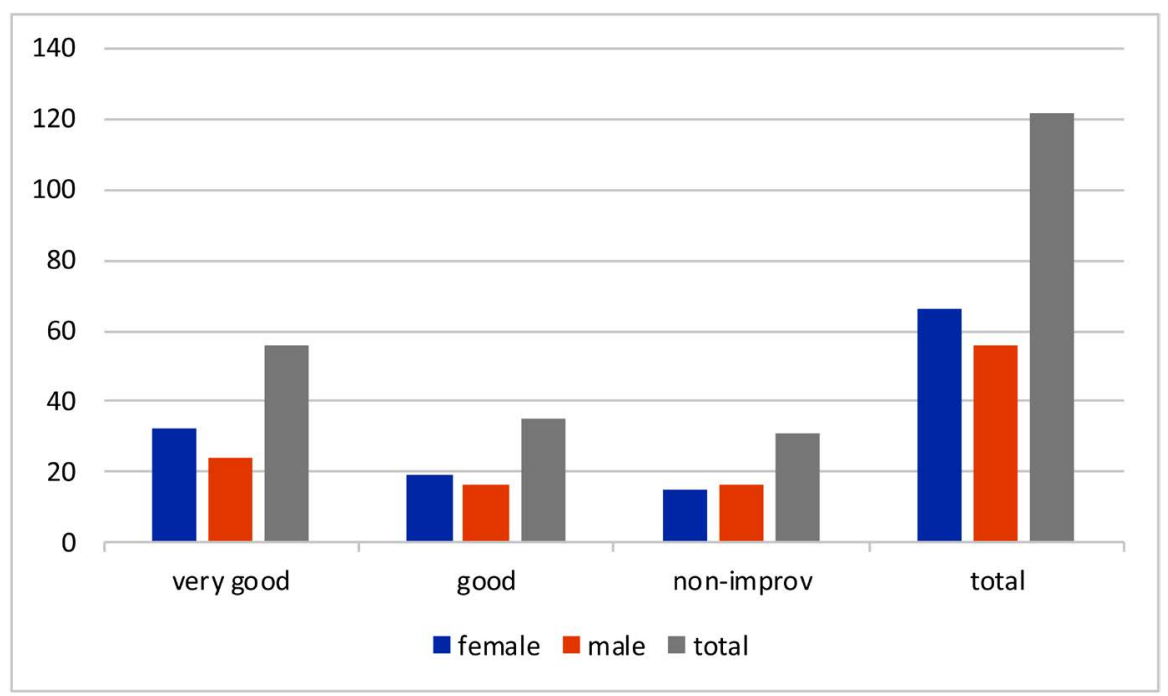

Figure 2. Relationship between male and female regarding the differences of improvement of acute Bell's palsy paralysis related to sex.

sis as shown in [1]. Most of the Bells palsy patients demonstrate facial nerve enhancement, usually in the tympanic and labyrinthine segments [11]. The electroacupuncture in treatment of acute stage peripheral facial paralysis is effective [12]. In this research the percentage of the improvement resulting from the electro- 


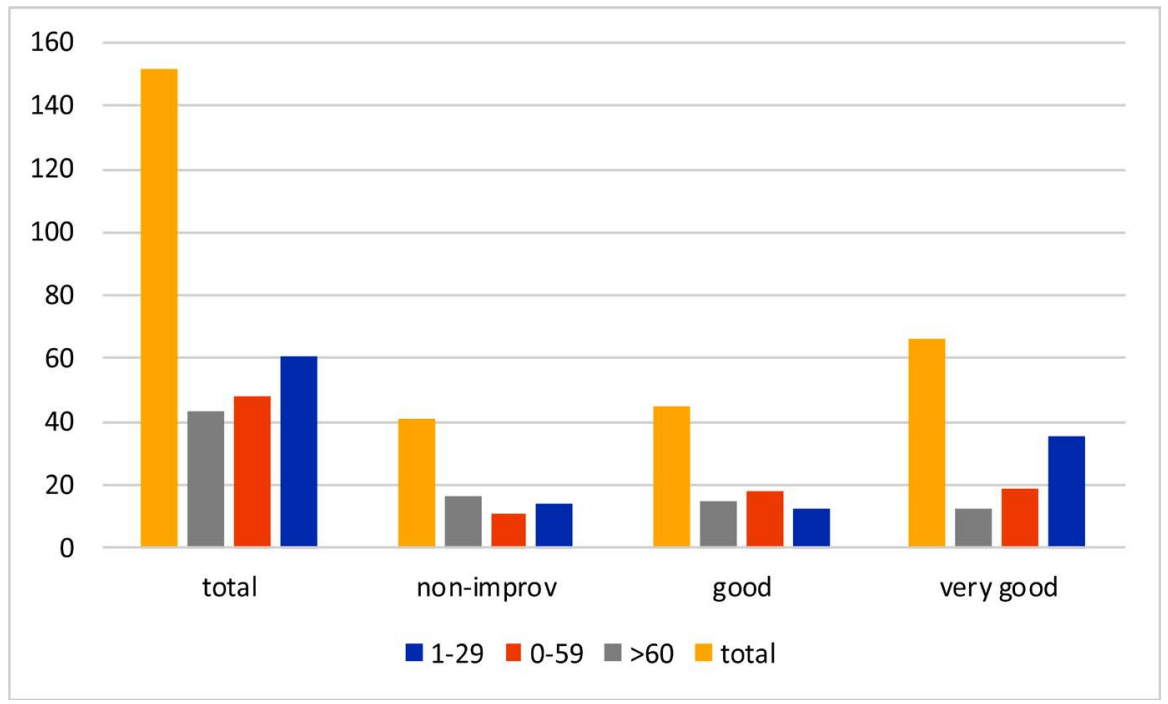

Figure 3. Relationship between male and female regarding the differences of improvement of acute Bell's palsy paralysis related to Age.

acupuncture with drug therapy shows very good improvement of Bell's palsy (58\%), good improvement (24\%), and non-improvement (18\%), during the first two weeks, and one month therapy, although the non-improved case also improved in the next month with only two cases that shows a resistant and take longer time of treatment with residual facial paralysis. The acupuncture treatment skill is an effective way for treating old facial paralysis [13]. This results supports that the acupuncture play an important role to cure the Bells palsy.

Comparing the effect of acupuncture therapy between female and male patients shows that there are no differences of the effect related to the sex as shown in Table 1. That's also documented in the treatment of Bell's palsy with steroid; there is no difference in incidence according to sex or season [14]. Improvement of acute Bell's palsy, related to the sex of the patients including in this research, shows that there is no significant relation-ship between males and females ( $\mathrm{P}$ more than 0.05), that's going with the above-mentioned documents. Although the numbers of the female's patients cured are greater than males, sex has no great role to play in the effects of acupuncture and drug therapy see Figure 2. Regarding the improvement of acute facial paralysis related to patients age which divided as three groups ( $1-29,30-59$, more than 60 years old) the results shows that the younger age group have a better chance to improve than the mild and elder age groups with statistical significant $(\mathrm{P}<0.01)$, may be due to a general body condition as activity, resistance to illness, ...etc. as shown in Table 1, and it's clear that the improvement in the young age group shows very good improvement than old age see Figure 3. From our results, still we agree that the quality of the induced trails was inadequate to allow a better conclusion about the efficacy.

\section{Conclusion}

Acupuncture is a choice for treatment of patients suffering from Bell's palsy. 
The electro-acupuncture in treatment of acute stage peripheral facial paralysis is effective and the improvement in the young age group shows very good improvement than old age.

\section{References}

[1] Baugh, R.F., Basura, G.J., Ishil, L.E., Schwaartz, S.R., Drumheller, C.M., Burkholder, R., et al. (2013) Clinical Practice Guideline; Bell's Palsy Executive Summery. Otolaryngology-Head and Neck Surgery, 149, 656-663. https://doi.org/10.1177/0194599813506835

[2] Li, Y. and Peng, C. (2000) Acupuncture Treatment Help Bell's Palsy. Journal of Traditional Chinese Medicine, 20, 33-35.

[3] Shehata, H.A., Okosun, H. and Okosun, H.A. (2004) Neurological Disorders in Pregnancy. Current Opinion in Obstetrics \& Gynecology, 16, 117-122. https://doi.org/10.1097/00001703-200404000-00004

[4] Kondev, L. and Miuster, A. (2003) Headach and Facial Pain in Children and Adolescents. Otolaryngologic Clinics of North America, 36, 1153-1170. https://doi.org/10.1016/S0030-6665(03)00123-3

[5] Gronseth, G.S. and Paduga, R. (2012) Evidence Based Guideline Update: Steroids and Antivirals for Bell's Palsy: Report of the Guideline Development Subcommittee of the American Academy of Neurology. Neurology, 79, 2209-2213. https://doi.org/10.1212/WNL.0b013e318275978c

[6] Singhi, P. and Jian, U. (2003) Bell's Palsy in Children. Seminars in Pediatric Neurology, 10, 289-297. https://doi.org/10.1016/S1071-9091(03)00077-9

[7] Halo, N., Matsumoto, S., Kisaki, H., Takahashi, H., et al. (2003) Efficacy of Early Treatment of Bell's Palsy with Oral Acyclovir and Prednisolone. Otology \& Neurotology, 24, 948-952.

[8] Prakosh, K.M. and Reymond, A.A. (2003) The Use of Nerve Conduction Studies in Determining the Short-Term Outcome of Bell's Palsy. Medical Journal of Malaysia, 58, 69-78.

[9] Sun, L. (2003) Clinical Experience in Electro-Acupuncture Treatment. Journal of Traditional Chinese Medicine, 23, 40-41.

[10] He, L., Zhou, D., Wu, B., Li, N. and Zhan, M.K. (2004) Acupuncture for Bell's Palsy. The Cochrane Database of Systematic Reviews, No. 1, CD002914.

[11] Navarrete, M.L., Rovira, A., Sancles, M.C. and Quesada, P. (1993) Bells Facial Paralysis Study with Magnetic Resonance and Gadolinium. Acta Otorrinolaringológica Española, 44, 95-100.

[12] Vrabec, J.T., Backous, D.D., Dajalilian, H.R., Gidley, P.W., Leonetti, J.P., Marzo, J., et al. (2009) Facial Nerve Grading System 2.0. Otolaryngology-Head and Neck Surgery, 140, 445-450. https://doi.org/10.1016/j.otohns.2008.12.031

[13] Xing, W., Yang, S. and Guo, X. (1994) Treating Old Facial Nerve Paralysis of 260 Cases with Acupuncture Treatment Skill of Pause and Regress in Six Parts. Zhen Ci Yan Jin, 19, 41-48.

[14] Rowland, S., Hooper, R., Hughes, R. and Burney, P. (2002) The Epidemiology and Treatment of Bell's Palsy in the UK. European Journal of Neurology, 9, 62-68. https://doi.org/10.1046/j.1468-1331.2002.00343.x 
Submit or recommend next manuscript to OALib Journal and we will provide best service for you:

- Publication frequency: Monthly

- 9 subject areas of science, technology and medicine

- Fair and rigorous peer-review system

- Fast publication process

- Article promotion in various social networking sites (LinkedIn, Facebook, Twitter, etc.)

- Maximum dissemination of your research work

Submit Your Paper Online: Click Here to Submit

Or Contact service@oalib.com 